\title{
Escritura y Potencia. Notas sobre Escrituras del no
}

\section{Writing and Potency. Notes on Writings of no}

\author{
Romina MAGALLANES \\ Universidad Nacional de Rosario \\ romina_magallanes@yahoo.com.ar
}

Recibido: 12-06-2015

Aceptado: 22-05-2016

\section{Resumen}

El presente trabajo se propone dar cuenta de la vinculación de los conceptos de escritura y potencia. En primer lugar, y principalmente, abordaremos de las teorizaciones de Giorgio Agamben; luego ensayaremos hipótesis sobre la índole material de tal vínculo sintetizadas en la expresión "escrituras del no", siguiendo algunas propuestas de Walter Benjamin, Jaques Derrida y Roland Barthes y Enrique VilaMatas, entre otros.

Palabras clave: Escritura, potencia, impotencia, materia, insignificancia.

\begin{abstract}
This paper aims to show the relationship of the concepts of writing and potency. First, from the theories of Giorgio Agamben; then presenting hypotheses about the physical nature of such a link synthesized in the expression " writings of no ", following the proposals of Walter Benjamin, Jacques Derrida, Roland Barthes and Enrique Vila-Matas, among others.
\end{abstract}

Keywords: Writing, potency, impotency, matter, insignificance. 
La filosofía es, de hecho, una firme reivindicación de la potencia, la construcción de una experiencia de lo posible como tal. No el pensamiento, sino la potencia de pensar, no la escritura, sino la hoja en blanco: esto es lo que la filosofía no quiere de ningún modo olvidar. G. Agamben. "Bartleby o de la contingencia"

A lo largo de la obra de Giorgio Agamben, se ponen en juego diversas referencias a la noción de escritura. Desde Idea de la prosa, hasta La potencia del pensamiento, la temática cruza sus escritos. Algunas veces, fusionada con la idea de lenguaje o lengua, otras con más precisiones; es el caso de lo que él denomina "escrituras de la potencia".

Estas inquietudes tienen lugar a partir de Idea de la prosa, de 1985. Allí, en el ensayo "Idea del estudio", el autor presenta ya lo que será desarrollado con rigor en su ensayo dedicado al relato de Melville, Bartteby el escribiente, denominado "Bartleby o de la contingencia", de 1993, y en El pensamiento de la potencia, de 2005. En "Idea del estudio", anota:

Pero la última y más ejemplar encarnación del estudio en nuestra doctrina no es el gran filólogo ni el santo doctor. Es más bien el estudiante tal como aparece en algunas novelas de Kafka o de Walser. Su prototipo se encuentra en el estudiante de Melville que está sentado en una habitación de bóveda baja, "parecida en todo a una tumba", con los codos sobre las rodillas y la frente entre las manos. Y su figura más extremada es Bartleby, el amanuense que ha dejado de escribir (...). Su gesto es el de una potencia que no precede sino que sigue a un acto, lo ha dejado para siempre a sus espaldas. ${ }^{1}$

Aquí se encuentra la primera aparición del personaje de Bartleby, y su vínculo con los dos términos sobre los que versa la presente lectura: la no escritura y la potencia.

En su trabajo dedicado exclusivamente al cuento de Herman Melville, el autor circunscribe la fórmula inquietante del personaje, preferiría no hacerlo, I would prefer not to, a una constelación filosófica conformada en torno a la problemáticas de la potencia y la escritura del no.

La zona que Agamben observa articulada por una serie de textos en los que ambos términos se encuentran íntimamente ligados, comienza a delinearse en el libro III del tratado Acerca del alma de Aristóteles (430a). Allí el filósofo se sirve de la imagen de la tablilla de escribir en la que aún no hay nada escrito para representar el modo de existencia de la pura potencia: "como una tablilla de escribir (grammatéion) en la cual nada está actualmente escrito, así ocurre con el nous".

\footnotetext{
1 Agamben, G., Idea de la prosa, Madrid, Editora Nacional, 2002, p. 43.
} 
Como bien indica nuestro autor, en el siglo IV a.C. el material escriturario consistía en una tablilla cubierta de una capa de cera y un punzón que grababa sobre ella.

El tardío léxico bizantino, Suda, anota que: "Aristóteles era el escriba de la naturaleza, cuya pluma se alimenta del pensamiento" 2 . Este comentario, realizado cuando la práctica de la escritura con pluma y tinta era dominante, provoca en Agamben la pregunta sobre cuál habría sido la causa de la definición del filósofo como un escriba y del pensamiento como un acto de escritura; y encuentra la respuesta en el párrafo 430a de De Anima, anteriormente citado, y en Metafísica, Lambda (1074b-15-35) donde se presenta la aporía del pensamiento mismo. Allí, Aristóteles señala el problemático modo de ser del pensamiento. Si éste, dice, no piensa nada, y se atiene a su potencia de no pensar no tendría nada de venerable, por otra parte, si pensase algo en acto se encontraría subordinado a aquello pensado por lo cual estaría determinado por algo distinto de su esencia, que consiste en ser en potencia. Agamben cita el pasaje:

$\mathrm{Y}$, tanto si su naturaleza es el pensamiento en potencia (el nous) como si es, por el contrario, el pensamiento en acto (nóesis), ¿en qué piensa? O bien en sí mismo, o bien en otra cosa (...) Así, pues, él piensa en sí mismo, si es el más excelente, y el pensamiento es pensamiento del pensamiento. ${ }^{3}$

Nuestro autor comenta este fragmento explicando que Aristóteles halla un camino intermedio entre pensar algo y no pensar nada, entre potencia y acto. No piensa ni un objeto ni nada "piensa una pura potencia (de pensar y de no pensar)"4.

A continuación se pregunta:

Pero la aporía resucita en cuanto ha sido resuelta: pues, en efecto, ¿qué significa que una potencia de pensar se piense a sí misma? ¿Cómo es posible pensar en acto una potencia pura? ¿Cómo es posible que una tablilla para escribir en la que nada hay escrito se vuelva sobre sí misma y se impresione? ${ }^{5}$

En esta instancia, Agamben recurre a la lectura de Alberto Magno, que considera una anticipación de la tesis de Wittgenstein sobre la imposibilidad de un metalenguaje:

Alberto ve claramente que decir que una inteligibilidad se capta a sí misma no puede significar su reificación, su escisión en un meta-entendimiento y un entendimiento-

\footnotetext{
2 Agamben, G., "Bartleby o de la contingencia" en Preferiría no hacerlo. Bartleby, el escribiente de Herman Melville, Valencia, Pre-Textos, 2009. p.93.

3 Ibidem, p. 106.

4 Ibidem p. 107.

5 Ibidem.
} 
objeto. La escritura del pensamiento no es aquella en la cual una mano extraña mueve la pluma que graba dócil cera: sucede más bien que, en el momento en que la receptividad siente, por así decirlo, el propio no sentir, en ese momento -escribe Alberto- es como si las letras se escribiesen solas en la tablilla. ${ }^{6}$

El nous no es una cosa, sino un ser puramente en potencia y el modo para representar esta existencia de la potencia es la imagen de la tablilla de escribir cuando aún no es escrita.

Agamben comenta:

Toda potencia de ser o de hacer algo es siempre, de hecho, para Aristóteles, al mismo tiempo potencia de no ser o de no hacer (dynamis me eínaii me energhéin), pues de otro modo la potencia se trascendería siempre en el acto y se confundiría con el (...) Esta "potencia del no" es el hilo secreto de la doctrina aristotélica de la potencia, lo que hace de toda potencia en cuanto tal una impotencia (you autóu kai katá to autó pàsa dynamis adynamía, Met. 1046a). ${ }^{7}$

Es decir que experimentar la potencia en sí misma, de llegar a ser o a hacer algo, es, a la vez, experimentar su impotencia, de no ser, de no hacer algo. La tablilla de escribir puede llegar a estar y no estar escrita. La experiencia de esa reunión entre el poder ser y no ser escritura es la experiencia de la potencia en cuanto tal.

A partir de este texto comienza a cimentarse ese espacio donde conviven escritura y potencia. Desde Aristóteles hasta Avicena, desde Scoto Erígena y Alberto Magno hasta los tratados cabalísticos de Abulafia, cruza la Antigüedad y la Edad Media y más. La tablilla de escribir, grammatéion, se traduce al latín como "tábula rasa", que desembocará en "el papel en blanco" de Locke: "supongamos que en principio la mente no sea otra cosa que lo que llamaríamos un papel en blanco sin caracteres, sin ninguna idea", y también en la frase hecha "hacer tabla rasa". Hasta llegar a Bartleby, "la última figura y más extrema" del escriba que no escribe, de la potencia perfecta. ${ }^{8}$

La de Bartleby es la prueba más extrema a la puede arriesgarse una criatura. Porque atenerse a la nada, al no ser, es ciertamente difícil, pero es la experiencia propia de ese ingrato huésped, el nihilismo, con quien hemos adquirido familiaridad hace tiempo. Y atenerse únicamente al ser y a su positividad necesaria también es difícil, pero, ¿no es este precisamente el sentido del complejo ceremonial de la onto-teología occidental, cuya moral mantiene una secreta solidaridad con el huésped al que quería expulsar? Ser capaz, desde una potencia pura, de soportar el "no más qué" entre el ser y la nada, demorarse hasta el final en la impotente posibilidad que sobrepasa a uno y a otra, ésta

6 Ibídem, p. 107-8.

7 Ibidem, p. 98.

8 Ibidem, p. 102. 
es la prueba de Bartleby (...) la potencia (...) prepara un experimento en el cual, al liberarse del principio de razón, se libera tanto del ser como del no ser, creando su propia ontología. ${ }^{9}$

Así, nuestro autor deja entrever la posibilidad de una ontología de la potencia enmarcada en su ámbito de contingencia. Lo contingente es lo que puede ser y no ser. Entre dos realidades opuestas en acto esto sería una contradicción, pero no ocurre en el ámbito de lo potente, donde conviven el ser y el ser no. La potencia y la impotencia.

En el primer artículo de El pensamiento de la potencia, "La cosa misma", Agamben encara la problemática de la escritura a partir de la Carta séptima de Platón, texto que, junto al Fedro, sostienen las tesis fundamentales del filósofo griego respecto a la práctica del graphein.

En el Fedro, Platón deja vislumbrar que la escritura "enferma" a todo escritor, que lo domina, lo seduce y provoca algo así como una grafomanía, ya que la escritura es un phármakon deinós. Si bien parece un "remedio" para la memoria, en realidad es un "veneno" y una "droga hipnótica y terrible”, según los tres sentidos del término, para quien escribe.

En dicho diálogo (257-277) ${ }^{10}$, como extremo de toda una línea genealógica de "mala fama"11 de la escritura en la literatura griega previa, Platón se pronuncia en su contra y la excluye de los ámbitos fundamentales: el alma, el conocimiento, la verdad, y el bien. Afirma que es una marca muerta que no piensa por sí misma, que se disemina por todos lados sin control, que, indisciplinada, se entrega a la deriva separándose del autor - quien es el único que puede defender su sentido único con la voz viva-y del contexto donde se produce. Su máxima virtud es ser mera suplencia, recordatorio representativo. Sin embargo, sus peligros son siempre mayores. Porque a pesar de su insignificancia, la escritura es un phármakon y es deinós: una

\footnotetext{
${ }^{9}$ Ibídem, pp. 118-9

10 Gil Fernández, L., Fedro, Edición bilingüe, traducción, notas y estudio preliminar, Madrid, Instituto de Estudios Políticos, 1970. En efecto, Sócrates padece la grafomanía desde el inicio del diálogo: él, quien nunca sale del centro de la ciudad, por primera vez lo hace siguiendo el escrito que Fedro trae consigo. Fedro al mostrárselo, dice Sócrates, ha encontrado un phármakon (droga, veneno, remedio) para hacerlo salir. Todo discurso escrito lo transforma en una 'bestia hambrienta': "tú, poniéndome delante biblion, podrías llevarme, parece, alrededor de toda el Ática y por cualquier otro lugar que se te ocurra (230d-e)". Esto ocurre porque Sócrates está enfermo por la escritura, como se dice en 228b: tiene la enfermedad de oír discursos, es amante de los discursos (228c refiriéndose a los textos que trae Fedro). La enfermedad y el amor se identifican a lo largo del diálogo, el amor es enfermedad humana y luego manía (locura divina), que transforma a quien la padece en alguien que no tiene el dominio de sí (231d); en terrible monstruo (240a). La enfermedad y el amor, temas de los discursos leídos y pronunciados en el diálogo, refieren a estados de alienación, de fuera de sí, los mismos que, según Platón, provoca la escritura. De ahí su peligro, su ser terrible (deinós)..

11 Ibidem.
} 
"droga terrible". Por un lado, perjudicial para los cimientos de la metafísica, con poderes de producción de simulacros que tienen consecuencias prácticas, ya que sus inscripciones posibilitan una manipulación de las palabras que pueden desmoronar sentidos, manipular lo real, fascinar, persuadir, construir, destruir, engañar, según el caso. Por otro lado, ese mismo poder fascinante se separa del escritor y se vuelve contra él, envolviéndolo y dejándolo subyugado ante sus ilusiones de virtud.

En efecto, el escritor parecería ser el primero en sufrir los efectos de la escritura. Platón mismo los padece al encontrarse en la paradoja de criticarla y deslegitimarla desde la misma escritura que, como lo muestra su extensa obra, no pudo dejar de producir.

En su Carta VII, advierte: (...) Cualquier persona seria se guardará muy mucho de confiar por escrito cuestiones serias... Mientras que si él hubiera confiado a caracteres escritos estas reflexiones como algo de gran importancia, entonces seguramente es que, 'no los dioses, sino los hombres, le han hecho perder la razón'12.

Sin embargo, él fue, quizás, su primer crítico y el primer grafómano.

A partir de estas inquietantes notas platónicas sobre la escritura, se abre un camino en el pensamiento occidental, que conduce a la preeminencia de la voz sobre lo escrito. La voz se liga al alma, al pensamiento del sentido, a la cosa, a la verdad, y lo escrito, cae fuera del conjunto como derivado, artificio retórico, vicio terrible y excesivo.

Este camino es recorrido por muchos otros. Ferdinand de Saussure, por su parte, creía que la acción de retorno de la escritura sobre el habla era "viciosa", "un hecho patológico", que una inversión de las relaciones naturales habría engendrado el culto perverso de la letra-imagen, la superstición de la letra, y lo consideraba un pecado de idolatría: "La perversión del artificio engendra monstruos. La escritura, como todas las lenguas artificiales que se querría fijar y sustraer a la historia viva de la lengua natural, participa de la monstruosidad" 13 .

Volviendo a El pensamiento de la potencia, en "La cosa misma", Agamben se detiene en el estatuto de la indecibilidad de la cosa misma:

Ya los más antiguos comentadores habían comprendido que en este problema está implícita una contradicción. Tenemos una glosa de un tardo escoliasta platónico que dice más o menos lo siguiente:

¿Por qué el maestro en el Fedro subestima la escritura y sin embargo desde el momento en que ha escrito, ha creído de algún modo apreciable su obra escrita? También aquí -se responde el escoliasta, él ha querido seguir la verdad: como la divinidad ha creado

\footnotetext{
12 Platón, “Carta VII”, en Diálogos, Madrid, Gredos, 1998.

13 Citado en Derrida, J., “Anagrammes”, en De la gramatología, Buenos Aires, Siglo XXI, 2003, p. 50. Sin embargo, y paradojalmente, usan la escritura para condenarla, son escritores.
} 
tanto las cosas invisibles como las que caen bajo la mirada, así él también ha dejado algunas cosas no escritas y otras escritas. ${ }^{14}$

Esta pregunta vale ciertamente también para la Carta Séptima. Aquí Platón escribiendo sobre aquello que se da al pensamiento y que no es para escribir, parece desafiar la debilidad del logos y desmentirse, de algún modo, a sí mismo ${ }^{15}$.

Y concluye que tal paradoja indica que para Platón la cosa misma si bien trasciende el lenguaje, sólo es posible en el lenguaje. La cosa misma sería la cosa del lenguaje. No un inefable. La cosa misma como algo no-lingüístico, solo puede ser pensado en el lenguaje:

La cosa misma no es una cosa: es la decibilidad, la apertura misma que está en cuestión en el lenguaje, que es el lenguaje, y que en el lenguaje constantemente suponemos y olvidamos, acaso porque ella misma es, en lo más íntimo, olvido y abandono de sí. ${ }^{16}$

En esta instancia, el autor vuelve a Aristóteles, en este caso a De interpretatione donde aparece la letra, el grámma. Allí, lee Agambem, la letra aparece como último interprete de la voz: "Ella es el último hermeneuta, más allá del cual no hay otra hermeneía posible: su límite"17. Siguiendo estudios de antiguos gramáticos sobre dicha obra de Aristóteles, señala que para ellos la letra era el elemento de la voz, la letra tiene el privilegio de la automostración, pero que se muestra en cuanto era en la voz, como un pasado. "El grámma es, así, la forma misma de la presuposición y nada más que eso"18.

El ensayo se cierra con un fragmento de Hölderlin, quien había citado a Suda en sus anotaciones a la traducción del Edipo Rey de Sófocles. Pero la cita cambia. Aristóteles: "Era el escriba de la naturaleza, que sumergía la pluma benévola". Ya no se sumergía en el pensamiento, el instrumento material de la escritura humana "está sola frente a su tarea, armada únicamente con su benevolencia"19.

A partir de aquí se abre un camino hacia el minucioso trabajo de Agamben sobre la relación entre escritura y materia, donde la materia ocupará un lugar central en la noción de escrituras de la potencia.

\footnotetext{
14 Ibídem. Para profundizar en la problemática de las Doctrinas no escritas ver Szlezák, T. (1997). Leer a Platón, Madrid, Alianza, 1997; Kennedy, G. The Art of Persuasion in Greece, London, Princeton University Press, 1963; Krämer, H. (1996). Platón y los fundamentos de la metafísica, Caracas, Monte Ávila, 1996.

15 Agamben, ibídem, pp. 18-9.

16 Op. cit. p. 20.

17 Ibidem, p. 25.

18 Ibídem.

19 Ibídem, p. 26.
} 
Con el mismo tono que apreciamos en el epígrafe del presente trabajo, concluye su texto: "Devolver a la cosa misma su lugar en el lenguaje y, a la vez, restituir la escritura a su dificultad, a su tarea poética en la redacción: ésta es la tarea de la filosofía que viene" 20 .

En el siguiente ensayo, "La idea de lenguaje", de la Potencia del pensamiento", Agamben se detiene en la idea de presuposición que anunciaba ya en "La cosa misma". Otra vez, la referencia al vínculo entre tal idea y la tarea de la filosofía: la filosofía es el discurso que puede hablar de todo "a condición de que hable ante todo del hecho de que se habla" 21 . Presupuesto que no puede pensarse a partir de la consideración del lenguaje como tema, es decir, un metalenguaje que hable del lenguaje. El pensamiento contemporáneo, y aquí Agamben se refiere fundamentalmente a Derrida, propone una morada originaria del lenguaje de índole negativa, poniendo a la escritura (como huella) en dicho origen, indicando, así, que el lenguaje es desde el principio una huella infinita.

En "Políticas del nombre propio"22, Derrida decía que escribir implica un ausentarse. El escritor es quien aparece como retirándose. La marca producida al escribir seguirá operando y produciendo, como una especie de máquina, se dará a leer y a reescribir tras la desaparición del escritor. Tal desaparición del escritor en la escritura, además, conlleva la no presencia del querer-decir del escritor, de su intención, de su querer-comunicar-esto. Una escritura es aquello que sigue funcionando aun cuando el autor no responda de ello, de lo que firmó. Su estructura radica en su iterabilidad, en su índole repetible, reiterable y legible a pesar de la desaparición absoluta de todo destinatario. Es decir que la muerte o posibilidad de muerte de los mismos (escritor y lector) está inscripta en la estructura de la escritura, esto implica que es ruptura de la presencia no su expresión ni su restitución.

La escritura, asimismo, sigue Derrida, encierra ausencia de contexto. Lo escrito no se agota en el presente de su inscripción, permanece, da lugar a una repetición más allá de la presencia del sujeto empíricamente determinado que haya producido la escritura en un contexto dado. Rompe con el contexto como conjunto de presencias que organizan el momento de su inscripción. Tanto con lo que puede llamarse contexto real: presente de la inscripción, del escritor, medio ambiente, horizonte de su experiencia y la intención, el querer decir que impulsaría la escritura; como del contexto semiótico e interno: por su iterabilidad puede tomarse un sintagma fuera del encadenamiento en el que está dado, puede ser inscripto, injertado en otras cadenas, puede ser cita. Ningún contexto puede cerrarse sobre él, la escritura se convier-

\footnotetext{
20 Ibídem.

21 Ibidem, p. 27.

22 Derrida, J., "Políticas del nombre propio" en La Filosofía como Institución, Barcelona, Ediciones Juan Granica, 1984, p. 73.
} 
te, así, en deriva ${ }^{23}$. Derrida socava, con esto, la acepción de la escritura-vehículo, medio de expresión y comunicación que extiende muy lejos tal campo. Socava, así, la interpretación presente en toda la historia de la filosofía: los hombres escriben para comunicar algo, su pensamiento, sus ideas, sus representaciones:

La historia de la escritura estará de acuerdo con una ley de economía mecánica: ganar el mayor espacio y tiempo por medio de la más cómoda abreviación; esto no tendrá nunca el menor efecto sobre la estructura y el contenido de sentido (de las ideas) a que deberá servir de vehículo. El mismo contenido, antes comunicado por gestos y sonidos, será transmitido en lo sucesivo por la escritura, y sucesivamente por diferentes modos de notación, desde la escritura pictográfica, hasta la escritura alfabética, pasando por la escritura jeroglífica de los egipcios y por la escritura ideográfica de los chinos.

El carácter representativo de la comunicación escrita -la escritura como cuadro, reproducción, imitación de su contenido- será el rasgo invariante de todos los progresos subsiguientes. El concepto de representación es indisociable aquí de los de comunicación y de expresión que he subrayado en el texto de Condillac. La representación, ciertamente, se complicará, se darán descansos y grados suplementarios, se convertirá en representación de representación en las escrituras jeroglíficas, ideográficas, luego fonéticasalfabéticas, pero la estructura representativa que señala el primer grado de la comunicación expresiva, la relación idea / signo, nunca será relevada ni transformada. ${ }^{24}$

En su interés no representativo de la escritura, Derrida deconstruye estos supuestos, puntualiza la posibilidad de la escritura de ser separada del referente o del significado, y con esto, de la comunicación y contexto. Pero, añade a esto algo más, esta es la estructura de toda marca, de todas las especies de signo y comunicación, por ello, toda marca aunque sea oral será un grafema. De este modo, la escritura descansa en su servicio como vehículo de los conceptos, subordinada a ellos. Y ellos mismos se mostrarán ahora como categorías acríticas destinadas a asegurar la autoridad de cierto discurso histórico. Por ello, afirma Derrida, asistimos al despliegue histórico de una escritura general de la cual el sistema del habla, de la conciencia, del sentido, de la presencia, de la verdad sería su efecto, a esta escritura la llama raíz grafemática: la permanencia no presente de una marca diferencial separada de su pretendida producción u origen". Y extiende esto a la experiencia en general "si aceptamos que no hay experiencia de presencia pura, sino sólo cadenas de marcas diferenciales 25 .

Y agrega:

23 Derrida, J., Mal de Archivo, Una impresión freudiana, Madrid, Editorial Trotta, 1997, pp. 247-372.

24 Ibidem, p. 350.

25 Ibídem, p. 372. 
Yo quería insistir sobre esta posibilidad, posibilidad de sacar y de injertar en una cita que pertenece a la estructura de toda marca, hablada o escrita, y que constituye toda marca en escritura antes mismo y fuera de todo horizonte de comunicación semiolinguístico; en escritura, es decir, en posibilidad de funcionamiento separado, en un cierto punto, de su querer-decir "original" y de su pertenencia a un contexto saturable y obligatorio. Todo signo, lingüístico o no lingüístico, hablado o escrito (en el sentido ordinario de esta oposición), en una unidad pequeña o grande, puede ser citado, puesto entre comillas; por ello puede romper con todo contexto dado, engendrar al infinito nuevos contextos, de manera absolutamente no saturable. Esto no supone que la marca valga fuera de contexto, sino al contrario, que no hay más que contextos sin ningún centro de anclaje absoluto. Esta citacionalidad, esta duplicación o duplicidad, esta iterabilidad de la marca no es un accidente o una anomalía, es eso (normal/anormal) sin lo cual una marca no podría siquiera tener un funcionamiento llamado "normal" ¿Qué sería una marca que no se pudiera citar? ¿Y cuyo origen no pudiera perderse en el camino?26

La índole de suplemento, derivado, parásito a partir de la cual se excluía a la escritura de los ámbitos fundamentales a los cuales servía como instrumento, los conceptos de identidad, sentido, vida, presencia, representación, se encontraría ahora en el lugar de condición de posibilidad de aquellos mismos. La escritura, en tanto raíz grafemática: cita, iterabilidad, ausencia, haría de ellos sus efectos. La escritura, así, sin que se trate de una reubicación de fundamentos, es puesta por Derrida en el "origen". Pero sin que se transforme en una instancia fundante. No es colocada en el lugar del habla, del lógos. Lo que ocurre es que se deconstruye su ley, sus jerarquías.

"Tocar el origen del lenguaje con un momento escritural viene a ser tachar el origen mismo. No eliminarlo ni conquistar su puesto, su lugar, sino dar al lugar, al lugar del origen, al lugar origen una deriva". 27

Agamben retomará este concepto de huella, que reunirá con el de materia y autorreferencialidad, pero tratando de abrir el horizonte de la perspectiva derridiana, intentado hacerse cargo, al menos en la postulación, de una tarea de la filosofía: la eliminación y liberación de todo presupuesto, la comprensión de lo incomprensible, un decir que no se hunda en lo indecible sino que "diga el lenguaje mismo y exponga sus límites"28.

Aquí Agamben acude a Benjamin, y a su rechazo a concebir al lenguaje como medio de comunicación que transmite un mensaje de un sujeto a otro, y su búsque-

\footnotetext{
26 Ibidem, p. 369.

27 Santos Guerrero, J., "Gerarquías. Una escritura del espacio", en Escritura e imagen, núm. 1, pp. 129-143. Madrid, Universidad Complutense de Madrid, 2005. p. 134.

28 Agamben, op. cit. 2000, p. 39.
} 
da de una lengua que no transmita nada sino a sí misma, una palabra que se haya liberado de la "extrañeza del sentido"29, pero que elimine lo indecible del lenguaje. A partir de aquí Agamben avanza sobre Derrida y la negatividad escrituraria atribuida al origen del lenguaje (huella, por lo tanto no-origen, o "tarea infinita") proponiendo la posibilidad de una efectiva construcción de esa región como tarea ética de todo hablante 30 .

Agamben, así, apuntará a una nueva concepción de la noción de escritura y hue$11 a^{31}$, ligada a la materia y a la potencia; y no como presupuestos sino como exposición.

\section{La escritura del no: El síndrome Bartleby. Autorreferencialidad y materia}

Enrique Vila-Matas indica que la literatura contemporánea se nutre de cierta atracción por la nada que provoca que los escritores no escriban, o que escriban poco o que renuncien a escribir. Vila-Matas denomina a este fenómeno "literatura del No, y también "el síndrome Bartleby".

Hace tiempo que rastreo el amplio espectro del síndrome de Bartleby en la literatura, hace tiempo que estudio la enfermedad, el mal endémico de las letras contemporáneas, la pulsión negativa o la atracción por la nada que hace que ciertos creadores, aun teniendo una conciencia literaria muy exigente (o quizás precisamente por eso), no lleguen a escribir nunca; o bien escriban uno o dos libros y luego renuncien a la escritura; o bien, tras poner en marcha sin problemas una obra en progreso, queden, un día, literalmente paralizados para siempre. 32

A través de un recorrido por "un puñado" heterogéneo de Bartlebys, de escritores tocados por esa fuerza negativa como Walser, Kafka, Musil, Beckett, Celan, Vila-Matas pone de relieve una literatura del no, una literatura que es la negación de sí misma.

Como lo explicita en Bartleby y compañia la idea del autor es justamente la siguiente:

Me dispongo, pues, a pasear por el laberinto del No, por los senderos de la más perturbadora y atractiva tendencia de la literaturas contemporáneas: una tendencia en la que

\footnotetext{
29 Agamben, op. cit. 2007, pp. 51-2.

30 Ibidem, p. 62

31 Su noción de huella dará lugar a un vínculo con su concepción de testimonio, anunciado ya en $L a$ potencia del pensamiento "El origen y el olvido": "Y huella es aquello que evoca un origen en el instante mismo que testimonia acerca de su desaparición" (262)

32 Vila-Matas, E.: Bartleby y compañía, Barcelona, Anagrama, 2009, p. 12.
} 
se encuentra el único camino que queda abierto a la auténtica creación literaria; una tendencia que se pregunta qué es la escritura y dónde está y que merodea alrededor de la imposibilidad de la misma y que dice la verdad sobre el estado de pronóstico grave -pero sumamente estimulante- de la literatura de este fin de milenio. ${ }^{33}$

En efecto, el autor sospecha que la enfermedad del no, no es catástrofe sino "danza de la que podrían estar surgiendo nuevas construcciones de sensibilidad"34.

En consonancia con esta idea Agamben indica en "Pardes. La escritura de la potencia", que existe hoy una "crisis terminológica", que dicha crisis es la "situación del pensamiento" y que implica una "diferente y decisiva experiencia del lenguaje" 35 . Tales acontecimientos son enmarcados por Agamben a partir del problema de la autorreferencialidad. Tal problemática es, para Agamben, la clave para comprender la nueva experiencia del lenguaje que acontece hoy. Esta experiencia consiste en que los términos se encuentran privados de su poder de denotar, de su referencia a objetos, sin embargo, aún significan. El modo de dicha significación es la autoreferencialidad

La autorreferencialidad no tiene que ver con la referencia a una subjetividad, el autó no remite a una identidad, sino que consiste en que los términos se significan a sí mismos, pero tampoco a su índole acústica o gráfica, sino que significan solo en tanto significan. Dice Agamben analizando la problemática en conceptos de Derrida:

En el esquema semiótico aliquid stat pro aliquo, A está por B, la intención no debe tener como objeto ni el primer alquid ni el segundo, sino ante todo el estar por. La aporía de la terminología derridiana es que, en ella, un estar por esta por un estar por, sin que nada pueda constituirse en la presencia como un objeto denotado. Pero con esto, la noción misma de sentido (del "estar por") entra en crisis. ${ }^{36}$

El "estar por" solo puede ser nombrado por la noción de huella. La huella, o materia, es el "entre" algo y nada: "Entre el padecer algo y el padecer nada, está la pasión de la propia pasividad. La huella (týpos, íchnos) es desde el principio el nombre de esta pasión de sí y eso de lo que en ella se hace experiencia es el acontecimiento de una materia" 37.

El nombre puede ser nombrado, dice Agamben, el lenguaje puede advenir a la palabra, y la escritura a la escritura:

\footnotetext{
33 Ibidem, pp. 12-3.

34 Ibídem, p 123

35 Agamben, op. cit. 2007, p. 443.

36 Ibidem, p. 452.

37 Ibidem, p. 462.
} 
porque la autorreferencia se desplaza sobre el plano de la potencia: lo referido no es ni la palabra como objeto, ni la palabra en cuanto denota en acto una cosa, sino una pura potencia de significar (y no significar), la tábula para escribir sobre la que nada está escrito. Pero esta no es la autorreferencia de un sentido, el significarse a sí mismo de un signo, sino el hacerse materia de una potencia, su mantenerse en la propia posibilidad... la materia puede existir como tal porque ella es la materialización de una potencia a través de la pasión (el týpos, la huella) de la propia impotencia. 38

La noción de huella derridiana es un puro tener-lugar, es la "experiencia de una materia inteligible"39. La escritura como huella es, justamente, la escritura de la potencia.

La potencia, que se dirige a sí misma, es una escritura absoluta, que nadie escribe: una potencia que se escribe por su misma potencia de no ser escrita, una tabula rasa que es impresionada por su misma receptividad y puede, así, no-escribirse. Según la genial intuición del comentario de Alberto Magno al De Anima: "Hoc simile est, sicut diceremus, quo litterae scribent se ipsas in tabula", "esto es como si dijéramos que las letras se escriben a sí mismas sobre la tabla"40.

Por el ello, como el mismo Agamben considera, la noción clave en este asunto es la de materia. La huella derridiana es repensada, así, como escritura de la potencia, "una potencia que puede y padece a sí misma, una tábula para escribir que padece no la impresión de una forma sino la impronta de la propia pasividad, de la propia amorfia"41. Esta escritura es el acontecer de la materia, el padecer la propia pasividad y el mantenerse en su misma posibilidad.

Ya en "Umbral" (Idea de la prosa), Agamben reflexionaba sobre el vínculo entre la escritura, la potencia y la impotencia, la materia:

Sobre Damascio, último escolarca en cargo de la escuela filosófica de Atenas cuando el emperador Justiniano en 529 decretó mediante un edicto el cierre de dicha escuela. Comenzó a escribir sobre el Principio único y supremo del Todo.

Damascio levantó un instante la mano y miró la tablilla en la que iba anotando sus pensamientos. De repente se acordó del pasaje del libro acerca del alma en el que el filósofo compara el intelecto en potencia a una tablilla sobre la que no hay nada escrito. ¿Cómo no lo había pensado antes? Eso era lo que día tras día había tratado inútilmente aferrar, esto era lo que sin descanso había perseguido tras el destello de aquel jalo indiscernible, cegador. El límite último que el pensamiento puede alcanzar no es un ser, no es un lugar o una cosa, por muy extensa que esté de toda cualidad, sino la absoluta potencia, la pura potencia de la representación misma: ¡la tablilla para escribir! Aquello

\footnotetext{
38 Ibidem.

39 Ibidem, pp. 463-4.

40 Ibidem, p. 461.

41 Ibidem, p 460.
} 
que hasta entonces había pensado como el Uno, como lo absolutamente Otro del pensamiento era en cambio sólo materia, sólo la potencia del pensamiento. Y todo el extenso volumen que, que la mano del amanuense iba llenando de caracteres, no era más que el intento de representar aquella tabla perfectamente rasa, sobre la que aún no había sido escrito nada. Por ello no lograba concluir su obra: aquello que no podía cesar de escribirse era la imagen de aquello que nunca cesaba de no escribirse. 42

Estas reflexiones están presentes desde el comienzo de la obra de Agamben, y otra vez, en su significativo libro, La idea de la prosa, que abre con el ensayo titulado "Idea de la materia". A propósito del mismo Ruvitoso dice que como en anteriores libros, Idea de la prosa aborda la cuestión de la experiencia del lenguaje tanto teórica como formalmente. La escritura allí vivifica formas como el aforismo, el cuento breve, el enigma, la fábula que exponen más que una teoría una experiencia:

De allí que, siguiendo un motivo benjaminiano, se aparte de la escritura académica habitual, no recurra a la utilización de notas y citas entre comillas e intercale entre sus capítulos imágenes dialécticas. En parte se trata, no de una simple elección de estilo, sino del mismo motivo de un experimentum linguae como experiencia de la materia o potencialidad de nuestro lenguaje en busca de un "uso libre" del lenguaje. 43

También L. De La Durantaye ${ }^{44}$, como indica Ruvitoso, sostiene que en Idea de la Prosa hay una confrontación con el problema de la representación, con la pura potencia de la representación 45 . La cuestión de la representación del pensamiento y sus límites.

El autor señala que en dicha obra existe discontinuidad entre los títulos y los textos. Entre otras, el ejemplo que nos interesa es de "La idea de pensamiento", donde se discute sobre signos de puntuación. Según el autor al hacer esto, Agamben encuentra en aquello sobre lo que cada idea versa algo fundamental sobre tal idea. "Notes, quotations marks, bibliographical references, see also's and the like refer to a subject of knowledge ensconced like a ventriloquist behind the speaking subject"46.

\footnotetext{
42 Agamben, op. cit., 2002, p. 14.

43 Ruvitoso, M., "Del estatuto de la obra de arte al misterio de la economía", en Deus Mortalis. Cuaderno de Filosofía Política. Bs. As: Instituto de Filosofía y Letras de la Facultad de Filosofía y Letras (UBA). N 9, 2010, pp. 9-27.

44 De La Durantaye, L., Giorgio Agamben: A Critical Introduction, Stanford University Press, Stanford. Cap IV: "The Pure Potentiality of Representation: Idea of Prose", 2009, pp. 121-155. En este sentido, su trabajo Lo que queda de Auschwitz. El archivo y el testigo. Homo Sacer III: Valencia: Pretextos, 2005 , p. 10, es presentado por el propio Agamben como un "comentario", una "suerte de comentario perpetuo sobre el testimonio".
}

45 De La Durantaye op. cit., 2009, p. 125.

46 Ibídem, p. 125. 
Es como si la misma escritura lo posibilitara, mostrase la idea en su materialidad. En efecto, en ese primer ensayo, "Idea de la materia", el autor muestra con completa claridad lo que intenta introducir el presente trabajo:

Donde acaba el lenguaje empieza, no lo indecible, sino la materia de la palabra. Quien nunca ha alcanzado, como en un sueño, esta lignaria sustancia de la lengua, a la que los antiguos llamaban "selva", es, aunque calle, prisionero de las representaciones. ${ }^{47}$

\section{Notas sobre materias escriturarias o escrituras del no}

Si expandimos la noción de escritura (y lectura) hacia otro plano donde el sentido no reina (únicamente), podremos ubicarnos -aunque solo sea de a ratos, haciendo un esfuerzo hacia la "locura", si esta es el afuera del $\log o s^{-48}$ a un costado de la concepción de la escritura entendida como una tecnología al servicio del logos, que se limita a reproducir. Es decir, que como subsidiaria del ser, de "lo dicho", lo vivido, la "propia vida", ella debería relatar, narrar, esas vivencias personales, los avatares de una mismidad que la precede y que la comanda.

No obstante, existen escrituras que se hacen eco de la "selva" y se sueltan de las representaciones, y se encuentra en ellas una materialidad inservible, insignificante: liberada de la servidumbre del significado - o también una urgencia por su destierro. Encontramos tradiciones y fugas, modos diversos de esta materialidad que expondremos en su singularidad. Las escrituras de W. Benjamin, R. Barthes, J. Derrida, R. Chartier, G. Agamben, entre otros trazan una extensa constelación de marcas que subrayan este matiz. Consideramos que las escrituras diarísticas de escritor pueden sumarse a esas tradiciones y fugas.

I. Walter Benjamin denominaba a su práctica "escritura dispersa": Verzettelte Schreiberei. El verbo verzetteln señala tanto un "malograr, dispersar, extraviar", "traspapelar", "anotar algo en cualquier lugar"; como un "método para hacer la información manejable"49. Y también llamaba a sus libretas zarteste Quartiere,

\footnotetext{
47 Agamben, op. cit., 2002, p. 17.

48 Marcelo Percia, en su artículo "Fantasías de la conducta y el sentimiento. Variaciones anti alegóricas", en Bartleby: preferiría no. Lo bio-político, lo post-humano, Córdoba, La Cebra, 2008, p.146. parece responder con cierta intempestiva, que inspira e intimida, a esta tradición: "La metástasis explicativa pone la vista la vana intención de controlar el sentido de una obra. Saturados de significados descansamos en paz. En algún momento, leer se vuelve un trabajo tedioso: como el hastío de los guardia cárceles que tienen todas las celdas controladas.

Practico la obstinación interpretativa como descalabro de sentido, como liberación de desvíos confinados, como abuso de la confianza argumental, como tormenta de asociaciones posibles e ilícitas $\mathrm{y}$, también, como exageración que da risa".

49 Wizisla, E. "Prólogo, ¿Pero cuándo se llegará a escribir libros como catálogos?”, en Archivos de Walter Benjamin. Fotografias, textos y dibujos, Madrid, Walter Benjamin Archiv, 2010, p. 23.
} 
"delicados alojamientos"; y a sus figuras gráficas, Konstellationen, constelaciones, "ordenaciones espaciales, bipolares o elípticas, en las que conceptos y figuras del pensamiento se relacionan entre sí por medio de tensiones" 50 . Y también indicaba un gusto por coleccionar residuos. Benjamin lo llamaba Lumpensammlung, una recolección de trapero, que "se propone salvar lo desechado por la historia" 51. Como también el "pasado espacializado", Raumgewordene Vergangenheit, cuando entran en la escritura, como otra de sus facetas, los diferentes tipos de letras, los documentos de diversa índole, los montajes, injertos de otros textos, cierta especie de álbum de recortes, los esquemas, los mapas, las fotografías, las postales 52 .

Existe, en su escritura -la diarística, los cuadernos de notas sobre la escritura y las palabras que aprendía su hijo Stephen, sus notas micrográficas, entre tantas- una amplitud, una distención de la misma, que también podría denominarse "disposición gráfica"; y toda esa colección de trapero está expuesta no como material a ser utilizado en una Obra, sino, por el contrario, como una escritura desaforada, dilatada, como una "selva".

II. Roland Barthes, en un texto denominado "Variaciones sobre la escritura", justamente contrapone los dos planos a los que nos hemos estado refiriendo, el de la ontología significativa y el de la materialidad insignificante. Sus trabajos, dice, atendieron durante mucho tiempo a la escritura entendida en sentido metafórico como una "variedad del estilo literario", o "el conjunto de signos lingüísticos mediante los cuales un escritor asume la responsabilidad histórica de su forma y se vincula con su trabajo verbal con cierta ideología del lenguaje"53.

Pero años más tarde, sigue Barthes, lo que le interesa es una especie de retorno hacia el cuerpo:

(...) es el sentido manual del término el que quiero abordar, es la 'escritura' (el acto muscular de escribir, de trazar letras) lo que me interesa: ese gesto por el cual la mano toma un instrumento (punzón, lápiz, pluma), lo apoya sobre una superficie y de manera pesada o acariciante traza formas regulares, recurrentes, ritmadas (no es necesario decir más: no hablamos necesariamente de "signos"). .54

\footnotetext{
50 Ibídem, p. 20.

51 Ibídem

52 Ibídem. Como muchos diaristas, es remarcable el caso de Ludwig Wittgenstein, quien llenaba sus diarios de fotografías, además de dibujos, esquemas. Tenía cuadernos de colección de fotografías, y así como con la imagen, los colores, Wittgenstein las vinculaba con la escritura y el lenguaje. "En la sistemática intemperie que enseña el diario íntimo, Ludwig Wittgenstein le tomó instantáneas al lenguaje y recorrió solo y descalzo las arenas insoladas y los gélidos lagos de misteriosas materias", en Serra Bradford, M., "Variaciones Wittgenstein. El arte de narrar", en Boletín 13-14 del Centro de Estudios de teoría y crítica literaria, Rosario, Facultad de Humanidades y Artes, Universidad Nacional de Rosario, 2007-8, p. 45. También, los diaristas Anais Nin, Idea Vilariño, Rodolfo Walsh, entre otros. 53 Barthes, 1989, p. 12.

54 Ibídem.
} 
Barthes cruza, así, aquellos planos. Incluso en uno de sus Diarios, "Deliberación", escribe "En un primer momento mientras escribo mis notas (cotidianas) experimento cierto placer: es sencillo, fácil. No hay que torturarse buscando qué decir"s5.

III. En Historia de la lectura en el mundo occidental, G. Cavallo y R. Chartier, realizan una genealogía detallada de la práctica de la lectura y escritura en occidente, que tiene dos ideas como criterio de composición: una de ellas es que "la lectura no está previamente inscrita en el texto", y la otra es que "un texto no existe más que porque existe un lector para conferirle significado" 56 . Los autores resaltan que el texto tiene un "estatuto inédito cuando cambian los soportes que le proponen a la lectura" 57.

La lectura no es solamente una operación intelectual abstracta: es una puesta a prueba del cuerpo, la inscripción en un espacio, la relación consigo mismo o con los demás. (...) Una historia de la lectura no tiene que limitarse únicamente a la genealogía de nuestra manera contemporánea de leer, en silencio y con los ojos. Implica igualmente, y quizás sobre todo, la tarea de recobrar los gestos olvidados, los hábitos desaparecidos. El reto es considerable, ya que revela no solo la distante rareza de prácticas antiguamente comunes, sino también el estatuto primero y específico de textos que fueron compuestos para lecturas que ya no son las de sus lectores de hoy.

Contra la representación elaborada por la propia literatura y recogida por la más cuantitativa de las historias del libro, según la cual el texto existe en sí, separado de toda materialidad, cabe recordar que no hay texto alguno fuera del soporte que permite leerle (o escucharle). Los autores no escriben libros: no, escriben textos que se transforman en objetos escritos -manuscritos, grabados, impresos y, hoy, informatizados- manejados de diversa manera por unos lectores de carne y hueso cuyas maneras de leer varían con arreglo a los tiempos, los lugares y los ámbitos. 58

Entre los diversos y múltiples cambios que tuvieron lugar durante la antigüedad y la Edad Media en la práctica escrituraria, existen tres acontecimientos -que son dejados de lado por las historias de los orígenes de los diarios- que, por lejanos, no dejan de habitar y trastocar la escritura diarística, como reinando en lo incumplido de esos "gestos olvidados", y resaltar su índole material, como también la íntima. Entre los siglos XI y XIII, la figura del copista, a quien también llamaban "pintor"59

\footnotetext{
55 Ibidem, p. 365.

56 Cavallo, G., y Chartier, R. (comp.), Historia de la lectura en el mundo occidental, Madrid, Taurus, 1998 p. 11.

57 Ibidem, p. 12.

58 Ibídem, pp. 15-6.
} 
toma completa relevancia, y con esto, la materialidad escrituraria, el trabajo manual, la postura corporal, los elementos, la imitación de las letras que el copista no lee significativamente, se imponen por sobre el sentido. No solo esto, ambos fenómenos se ligan, por otra parte, a la aparición del espacio de la intimidad 60 .

La desconexión entre escritura y sentido, entre medio de expresión o comunicación y contenido se manifiesta en diferentes facetas. Por un lado, tiene lugar la transformación de la práctica de la escritura en una especie de actividad salvadora, "la fatiga de transcribir era de por sí "una oración realizada no con la boca sino con las manos" (Pedro El Venerable, Epist., I, 20). Es decir que más allá de su significado, toma relieve el acto somático de escribir mismo, y una implicación performativa, ya que el ejercicio caligráfico de copia tiene por efecto no la comprensión lectora sino la salvación del alma. Por otra parte, tiene lugar una modificación clave que posibilitó otros tipos de lectura: la separación de las palabras, o la "palabra discontinua"; y con ella una serie de compendios como el espacio-página dividido en dos columnas, rubricaciones, signos de párrafo, texto y comentario, sumarios, concordancia de términos, índices. Dicha disposición visual, novedosa también conlleva performatividad, ya que, como indica Saenger, ella se presenta como condición de posibilidad de una conciencia crítica, de la elaboración del pensamiento ${ }^{61}$. La separación de las palabras dio lugar, por primera vez, a un vínculo de intimidad entre el autor y su manuscrito, "despertó el interés por la composición autógrafa" (...) Autores "expresaron sentimientos íntimos hasta entonces no reflejados en pergamino debido a la ausencia de confidencialidad impuesta por el hecho de tener que dictar los textos a un secretario". Otros elementos que promovieron dicha intimidad fueron las anotaciones añadidas, tachaduras, correcciones que "formaban un nuevo género de testimonios literarios"62. Autores como Guiberto de Nogent escribían sus sueños y otros sentimientos íntimos con la finalidad de mantenerlos en secreto. Asimismo, la modificación en la letra fue decisiva para la construcción de ese espacio íntimo:

\footnotetext{
59 Saenger, P., "La lectura en los últimos siglos de la Edad Media" en Cavallo, G., y Chartier, R. (comp.), Historia de la lectura en el mundo occidental, Madrid, Taurus, 1998, p. 201.

60 Crf. Catelli, N., En la era de la intimidad. Seguido de: El espacio autobiográfico, Rosario, Beatriz Viterbo, 2007. En su trabajo la autora platea otros vínculos históricos entre escritura e intimidad, 2007, pp. 9-26.

61 Saenger, op. cit. pp. 33-4. Crf. Walter Ong, W., Oralidad y escritura. Tecnologías de la palabra, Buenos Aires, Fondo de Cultura Económica, 2000. Havelock, E. A. ,La musa aprende a escribir, Barcelona, Paidós, 1996. Svenbro, J. "La Grecia arcaica y clásica. La invención de la lectura silenciosa" en Cavallo, G. y Chartier, R. en Historia de la lectura en el mundo occidental. Madrid: Taurus; 2001, pp. 59-93.

62 Saenger, op. cit. p 196.
} 
escribir en gótica cursiva informal sobre folios y cuadernillos reunidos sin normas rígidas hacía el acto físico de escribir menos laborioso y más compatible con la actividad intelectual (...) El autor representado en las miniaturas, solo en su estudio o a veces en un escenario pastoral idílico, empleando la gótica cursiva, se libraba al mismo tiempo de la fatiga de escribir y de la dependencia de los copistas. La nueva simplicidad de la escritura dio al autor una mayor sensación de intimidad y privacidad. ${ }^{63}$

Por último, otra modificación en la noción y práctica de la escritura: las aristocracias europeas eruditas hacían hincapié en el libro considerado como objeto de adorno, de ostentación de riqueza. Así, se encargaban libros con encuadernaciones realizadas con pieles valiosas, telas finas, metales preciosos 64 .

IV. El diarista Walter Benjamin exalta estos gestos repetidamente. El fervor coleccionista de libros, de objetos, se entrevera en una mezcla escrituraria con sus micrografías, las notas sobre las palabras aprendidas de su hijo Stephen, sus paseos y los objetos postales y fotográficos en Moscú. El ornamento de la letra, su trabajo de tesoros encontrados en lapiceras óptimas - o la estilográfica que Benjamin describe como una "encantadora criatura con la que podré realizar todos mis sueños y desplegar una productividad que en tiempo de la antigua -pluma- hubiera sido imposible"65 - posturas corporales, papeles, cuadernos, máquinas de escribir, colores conforman la escritura diarística como el carozo dentro de su fruta, de Rilke. Nuestra contemporánea manera de leer no repara en estas formas de escritura que se encuentran en lo que llamamos escritura diarística. Pero ellas conviven también con las escrituras de la potencia, las escrituras del no, como materia en su peculiar disciplina escrituraria llevada con tesón, muchas veces contra la voluntad o sin comprender por qué se escribe eso que se escribe, un diario, un tamaño minúsculo de marcas, una descarga de incomodidad ilegible, dibujos.

Por ello, el garabato es una figura afín a la marca de la escritura diarística antes que el dibujo significativo. Porque en el garabato no hay sentido que reduzca a las huellas, es una marca que no da forma, no escribe algo, no se actualiza en un sentido. Los garabatos son gestos amorfos, insignificantes 66 . Las huellas están allí como potencia absoluta.

Ciertamente, las escrituras diarísticas significan pero en eso se cuela la imparable insignificancia. Adriana Astutti apunta un matiz de esta insignificancia en la escritura diarísitica en El discurso vacío de Mario Levrero. Allí, dice, lo que más se

\footnotetext{
63 Ibidem, p. 204.

${ }^{64}$ Cavallo, Chartier, op. cit. 2001, p. 35.

65 Benjamin, W. en Marx, U., "De lo pequeño a lo minúsculo. Micrografías", en Archivos de Walter Benjamin. Fotografias, textos y dibujos, Madrid, Walter Benjamin Archiv, 2010, p. 55.

66 Freire, H., "La escritura: ¿espacio liso o estriado?" en Escritura e imagen, núm. 1, pp. 159-177, Madrid, Universidad Complutense de Madrid, 2005, p. 162. Cfr. Blanchot, M. El libro que vendrá, Caracas, Monte Ávila, 1969, p 209: "El interés del diario reside en su insignificancia".
} 
destaca es el trazo, el dibujo de la palabra, el trabajo de marcar, el modo, la fuerza de la mano, la velocidad con que se lleva a cabo la inscripción, la postura antes que el sentido de lo que se escribe, lo que se escribe se hace desde la materialidad de la letra, la birome, la tinta y de espaldas al querer decir, a las intenciones, imágenes y relaciones entre ellas ${ }^{67}$. Como la siguiente entrada del diario del poeta Pablo Pérez: "Confieso que ahora estoy jugando a perder la personalidad y a hacer una caligrafía standard, porque pienso que concentrándome en la caligrafía podría olvidarme de mí"68.

O la siguiente entrada del diario de Rodolfo Walsh: el 30 de abril de 1972: "Nuevo Diario. Este año hemos vuelto, on a retourné ce tan, this year we've come back to the island, l'ile, la isla. Escribo con la punta de tres dedos de cada mano, lentamente, como si aprendiera dactilografía (...)"69.

Y del diario de Rosa Chacel, el 9 de julio de 1955 y el 29 de diciembre de 1956: "Además, no sé por qué, la mano no me obedece. Todo lo que va escrito aquí es casi ininteligible" 70 .

El discurso autobiográfico como lector de la escritura diarística, aparece como un relato posicionado entre los conceptos de historia, sentido, totalización, unidad, vida e identidad. Mientras que, la escritura diarística en este aspecto material, potencial, opera sobre dicho discurso una deconstrucción. La escritura como (im)potencia des-sedimenta la concepción representativa expresiva de la escritura como órganon, como instrumento de comunicación y significación y con esto restituye la pura (im)potencia como posibilidad entre ser y no ser, entre escribir y escribir no.

Como subraya Blanchot, el diarista no escribe ni vive, pero escribe la reunión del no escribir y no vivir con la posibilidad de escribir y vivir. Es decir que la escritura no es subsidiaria de la vida, ni de la vida vivida. No se encuentran estas instancias en el lugar de fundamento de la escritura, que a modo de diligencia, de útil da cuenta de ellos. Antes bien, la escritura tendría lugar como el espacio inservible -no servil- donde todo ello se restituye a su ser y ser-no, a su posibilidad. Los escritores diaristas se aúnan al "síndrome Bartleby".

En un bellísimo breve texto, "El vino del mediodía. Las dos lapiceras" Nora Avaro nota una peculiaridad inquietante en el Diario de K. Mansfield:

\footnotetext{
67 Astutti, A., "Ejercicios de caligrafía: Mario Levrero", en Boletín 13-14 del Centro de Estudios de teoría y crítica literaria, Rosario, Facultad de Humanidades y Artes, Universidad Nacional de Rosario, 2007-8, p. 70.

68 Pérez, P., Un año sin amor. Diario del sida, Buenos Aires, Perfil, 1998, p. 187.

69 Walsh, R., Ese hombre y otros papeles personales, Buenos Aires, Ediciones de la Flor, 2007, p. 229.

70 Chacel, R., Obra completa. Volumen IX. Diarios. Valladolid, Fundación Jorge Guillén, 2004. p. 67.
} 
El 20 de setiembre de 1918 Katherine Mansfield escribe en su diario: "Espero que esta lapicera funcione. Sí.” La frase es despampanante, la vedette de las frases de un diario. ¿En qué exacto momento Mansfield comprueba que la lapicera funciona? ¿Trazando ya qué letra? ¿Cuándo? (...) una diarista de lucidez tan radical como Mansfield no puede dejar de escribir su sospecha de que la lapicera funcione con una lapicera que sí funciona, que ya funciona. 71

En ese exacto secreto irrumpe la impotencia de la escritura. Todo parece comenzar como si se requiriese la escritura para des-escribir, decir que no se puede decir, marcar sentido para exponer un hartazgo de su reinado y su afuera. Cuando de pronto, por momentos, ocurre una suspensión. Las letras aprendidas se agrandan, se tachan "con saña"72, se dibujan los puntos de íes como círculos, en los diarios de Walsh, se achican, se rrrrepiten 73 se colorean, comienzan a des-formarse, a expandir su trazo hasta alcanzar el garabateo, el dibujo, marcas matizadas, fotografías, objetos, se rompe una hoja. La materia. El sentido se extravía y una impotente materia tiene lugar ${ }^{74}$.

Así, la materialidad se expone en su impotencia, en su privación de realización totalizadora representativa, en su "no" al sentido normalizador de la escritura y la lectura, a la disciplina editorial. Y en todos los "in" que liberan un modo inquietante de leer y trazar el graphein se presenta aquella experiencia que Agamben y otros denominan potencia.

71 Avaro, N. 2004, mimeo.

72 Larre Borges, A, en Idea Vilariño. Diario de juventud, Montevideo, Cal y Canto, 2013, p. 19.

73 Pizarnik, A. en Diarios, Barcelona, Lumen, 2003, p. 19.

74 Serra Bradford, M., en su trabajo sobre los Diarios de Ludwig Wittgenstein, op. cit., realiza una enumeración atropellada, anárquica de lo que es, lo que pasa, lo que hace un Diario. Entre sus inventarios, muchos ya indicados en el estado de cuestión y otros apartados de este trabajo, dice: "Un diario lo hace la caligrafía. El color de la tinta, el trazo de la pluma, el tamaño de un cuaderno (...) El diario íntimo como esténcil: el recorte de una figura, escena, rapto, creación de un vacío al que se procederá a aplicar un color (...) En su estado edénico, no presupone fecha de entrega ni pie de imprenta”, 2000, p. 36. 